\title{
A country-specific evaluation on the feasibility of autonomous vehicles
}

\author{
Tatiana Novaes Theoto, Paulo Carlos Kaminski \\ Departamento de Engenharia Mecânica, Escola Politécnica, Universidade de São Paulo - USP \\ e-mails: t.theoto@gmail.com, pckamins@usp.br
}

\begin{abstract}
: this article aims to map and analyse country-specific factors, which enable autonomous mobility. In order to do so, a case study evaluation of the degree of preparation of nine selected countries for the advent of autonomous vehicles was conducted: Australia, Brazil, China, Germany, Japan, Singapore, South Africa, United Arab Emirates and the United States of America. Adoption models of this new technology are discussed, as well as its potential limitations. Finally, best practices and public policy recommendations are identified. The method includes a systematic review of literature, elaboration of evaluation criteria based on implementation assumptions, and a multi-criteria decision process to rank the countries.
\end{abstract}

Keywords: autonomous vehicles, driverless cars, systematic review, public policies, automation.

\section{Introduction}

\subsection{Motivation}

Driver alert devices, assist features, and advanced driver assistance systems (ADAS), which support drivers with the dynamic driving task, are becoming increasingly widespread (UNITED NATIONS ECONOMIC AND SOCIAL COUNCIL, 2017). As it is known that over $90 \%$ of road traffic accidents involve some sort of human error in USA, according to NHTSA (NATIONAL HIGHWAY TRAFFIC SAFETY ADMINISTRATION, 2017), the development of sophisticated assistance and automated driving systems vows to improve road traffic security (KALRA; PADDOCK, 2016). The fully autonomous vehicle (AV) represents the final stage of such evolution, when the driver is completely excluded from the vehicle's control loop. Not only will some components become obsolete (e.g. steering wheel, pedals), but also the mobility structure could change dramatically less congestion, more efficient use of road space, reduced fuel consumption and a democratization of mobility are among the expected benefits of the AVs (FAGNANT; KOCKELMAN, 2015).

Even though the concept of a driverless vehicle is not novel - reports trace the idea back to 1939's World Fair (VANDERBILT, 2018) - investments and research in the topic have recently bloomed. Just after 2003, when the United States Defence Advanced Research Projects Agency (DARPA) held the first "Grand Challenge" about the topic, reuniting academia and the automotive industry, autonomous vehicle research gained momentum (ENG, 2017). Since then, the Society of American Engineers (SAE) categorizes automation in five distinct levels, from ADAS (Level 1 and 2) to full automation (Level 5), as Figure 1 shows (NATIONAL
HIGHWAY TRAFFIC SAFETY ADMINISTRATION, 2017).

Because of the heightened interest and potential benefits, original equipment manufacturers (OEMs), suppliers, start-ups, tech companies, universities, governments, have been the key players in this revolution (ANDERSON et al., 2014). A long list of newcomers promises to define the future of transportation by enabling AV-related technology and businesses. Not only the large amount of firms is relevant, but also the incumbent business models, services, and industries linked to autonomous mobility concept, e.g. cybersecurity companies, mapping services and even intelligent manufacturing (OHNEMUS; PERL, 2016).

By leveraging their immense capabilities, knowledge, and market power, OEMs were also able to adapt to fit in this ever-changing landscape. Figure 2 (ABUELSAMID; ALEXANDER; JERRAM, 2017) illustrates the current leader board of autonomous driving, based on the companies' vision, go-to-market strategy, partnerships, production, technology, sales, product capability, quality, portfolio, and staying power. OEMs lead the autonomous mobility revolution, when compared to tier one suppliers (e.g., Delphi) and non-traditional entrants (e.g., Uber). Even though business models and the roles of each player are not exactly clear (ACCENTURE, 2015) - for instance, will OEMs act as asset suppliers or service providers? - the importance of such technology is already apparent (LUSTGARTEN; LE VINE, 2018).

However, in this optimistic scenario, where research and investments in autonomy are flourishing, benefits and expectations around $\mathrm{AVs}$ are often overestimated. Companies and governments state that AVs could be implemented as early as in 2020 (PARDI; CALABRESE, 2018), but delayed 


\section{SAE AUTOMATION LEVELS}

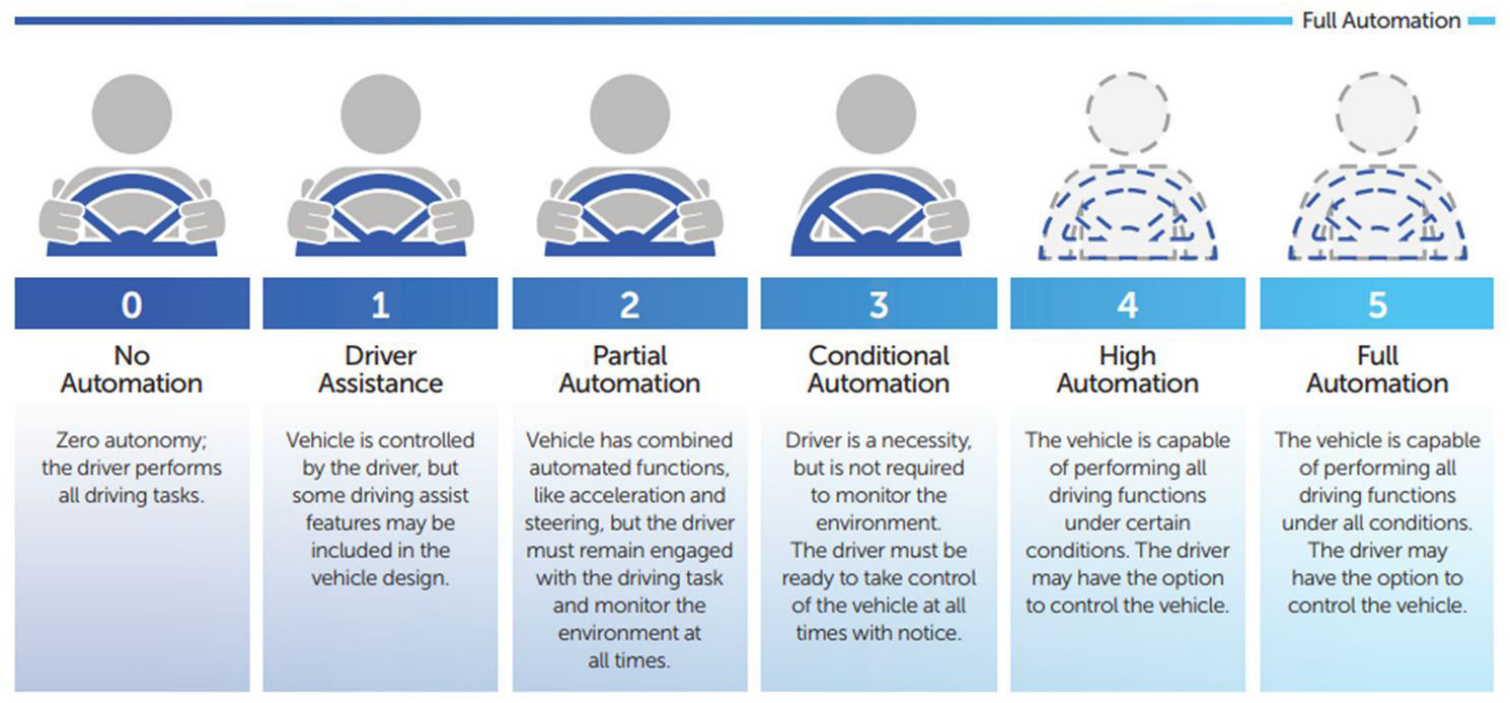

Figure 1. Distinct SAE Automation Levels (NATIONAL HIGHWAY TRAFFIC SAFETY ADMINISTRATION, 2017).

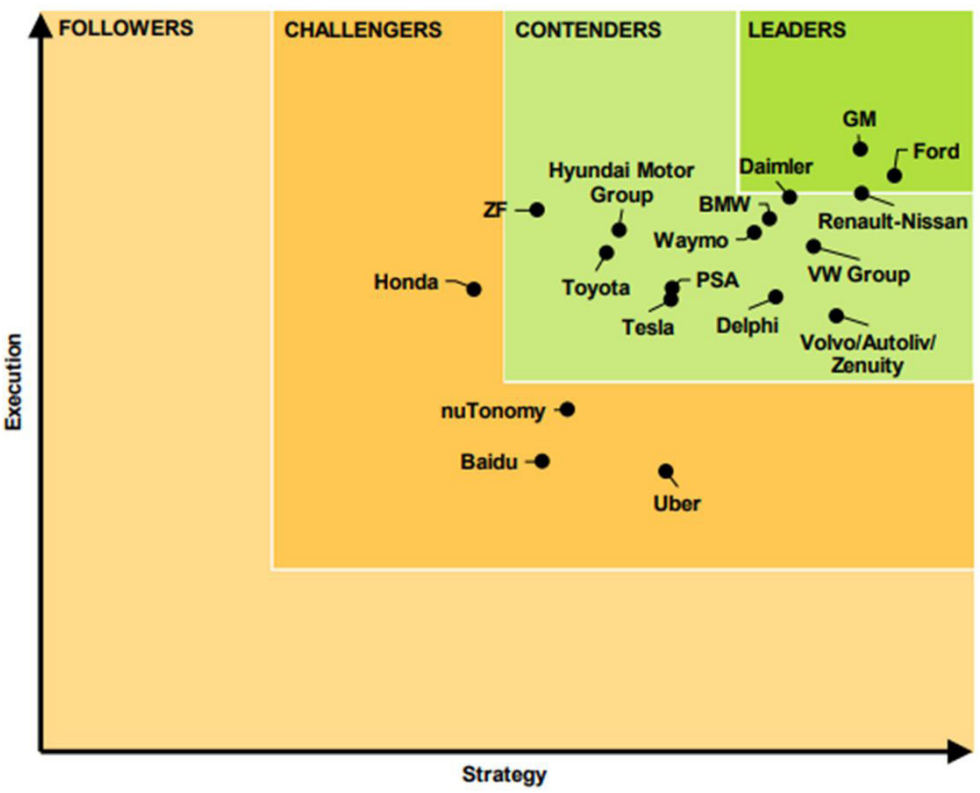

Figure 2. Leader board for autonomous driving (ABUELSAMID; ALEXANDER; JERRAN, 2017).

testing schedules (RANDALL, 2018) and fatal accidents involving conditional automated vehicles generate scepticism (KNIGHT, 2018). While the Vienna Convention on Road Traffic (UNITED NATIONS ECONOMIC AND SOCIAL COUNCIL, 2017) defines a true level 5 vehicle as capable of undertaking any journey from any starting point to any destination without geographic limitations, some believe that AVs will have to be restricted to defined use cases, such as campus shuttles or single route taxis in order to be feasible.

As Litman (2018) observes, full AV implementation depends on a set of requirements, which are crucial to realize autonomous mobility expected advantages. Yet, technology is not the only driver of such perquisites; socialtechnical aspects, as driver behaviour, public acceptance, regulations and infrastructure, are also fundamental AV enablers (CLAMMAN, et al. 2017; ENG, 2017; FUJIMOTO, 2014). These region-bound factors make an evenly spread AV revolution around the world extremely unlikely (BAGLOEE et al., 2016; IBUSUKI; KOBAYASHI; KAMINSKI, 2012).

In order to evaluate the current landscape of autonomous mobility, and how countries should deal with the ongoing 
revolution, industry reports, policy recommendations, and international laws were consulted. Despite their considerable amount, the majority of such reports is restricted to expositive content-Bloomberg's "Initiatives on Cities and Autonomous Vehicles" (BLOOMBERG, 2018), for instance, provides detailed information about current actions around the globe to prepare cities for autonomous mobility, but does not provide any trend analysis. "Revolution in the driver's seat: the road to autonomous vehicles", a report by The Boston Consulting Group (THE BOSTON CONSULTING GROUP, 2015a), provides valuable insights on how to analyse a country's AVrelated capabilities and acceptance. By conducting consumer interviews and using ADAS adoption rates as a proxy, the consulting firm predicted $\mathrm{AV}$ market penetration rates, and which countries will likely become first movers. A following report, "Revolution versus Regulation" (THE BOSTON CONSULTING GROUP, 2015b), divides ramifications of AV implementation in four categories - technical challenges, societal acceptance, legal issues, and pilot programs - and focuses on how to overcome such roadblocks. Furthermore, it analyses how U.S. and selected European countries are dealing with such concerns. However, its effective output is an agenda for countries to prepare themselves for autonomous mobility. KPMG's report “Autonomous Vehicle Readiness Index (AVRI)" (KLYNVELD PEAT MARWICK GOERDELER, 2018) builds up on BCG's list of concerns, and creates an index to assess twenty countries' openness and preparedness for autonomous vehicles. Policies' evaluation happened on-site, by leveraging the consulting firm's global footprint. Its four analysis topics - Policy and legislation, Technology and Innovation, Infrastructure, and Consumer acceptance - are divided in measurable metrics. The report fails, however, to justify thoroughly the choice for its metrics, as well as to measure the relative importance of each topic in the index calculation.

Thus, this imbalanced potential ought to be mapped in order to facilitate local discussions about AV implementation. Analysing the relationship of future AV technology and the current road traffic context is a fundamental step to ensure an optimal development locally. In this scenario, the first step is to define which conditions maximize the benefits of $\mathrm{AVs}$ and reduce the cost associated to their implementation. Then, the assessment of selected countries' readiness for AVs becomes feasible, and it provides policymakers and key stakeholders with a comprehensive overview to guide investments and policies.

\subsection{Aim and scope}

AV-related research has mainly focused on the technical aspects - e.g., hardware and software issues, system architecture. However, unless certain infrastructural, social, and economic conditions are met, it is almost impossible to implement any sustainable and efficient AV transportation system. The goal of the present article is to map the conditions and enabling factors for the establishment of $\mathrm{AVs}$ and evaluate their presence locally.

In order to do so, the following steps are followed:

(1) Define the evolving automotive technology landscape and possible business models;

(2) Understand the enabling factors and conditions that affect $\mathrm{AV}$ readiness levels;

(3) Create evaluation metrics to assess local capabilities for AV deployment;

(4) Select significant countries for the case study analysis;

(5) Evaluate the selected regions AV-readiness levels and capabilities, and calculate an index that objectively represents their performance;

(6) Provide recommendations and a benchmark of current enablers of AV technologies.

A lack of meaningful publications and scientific work was noted within this particular research topic. The current efforts are too pulverized, and a systematic, country-specific evaluation of such conditions is, to the author's knowledge, yet to be done. Thus, by evaluating selected regions AV-readiness levels and capabilities, and calculating an index that objectively represents their performance, the present article provides recommendations and a benchmark of best practices on AV-related policies.

\subsection{Outline}

This paper presents the methods used in the next section. Then, the criteria and country definition are discussed. The following section discusses the results. Finally, the conclusions and insights from the study are examined.

The article is organized in five sections. The second section describes the methods that are used to evaluate assumptions surrounding AVs. The third section reports the main requirements in country evaluation metrics and, consequently, evaluation criteria. The fourth section presents the results of the countries' evaluation regarding their AV-readiness. Finally the fifth section presents the conclusions, results and recommendations.

\section{Methods}

In order to reach the aforementioned goal, a few methods are necessary. Besides a systematic literature review to obtain insights and evaluate assumptions surrounding $\mathrm{AVs}$, the well-established weighted sum method (WSM) for multi-criteria decision analysis (MCDA), as defined by Saaty (1980) and Triantaphyllou (2000), is used. The following subsections explain the methods in detail. 


\subsection{Systematic literature review}

The literature review provided the necessary input for the countries' evaluation, by defining the requirements and conditions for a successful AV implementation, when the expected benefits of autonomous mobility are fulfilled.

The research was partially conducted in Singapore, where the author had access to multiple databases (e.g., IEEE, TRID) and journals (e.g., Journal of Modern Transportation), as well as to a network of AV specialists. Due to the low number of papers dealing specifically with this sort of evaluation, the research was extended to country's reports, consulting papers, and other non-academic sources, to contribute to the state-of-the-art evaluation.

Besides setting the foundation to the evaluation criteria, the literature review proved itself useful later, to investigate the countries' conditions thoroughly. Federal institutions and research groups, as the World Economic Forum (WEF), provided the majority of information.

\subsection{Multi criteria decision method}

In a WSM multi-criteria decision method, there are four fundamental steps, which involve the numerical analysis of alternatives (TRIANTAPHYLLOU, 2000):

(1) Determine the relevant criteria (Ci) and alternatives (Ai);

(2) Attach numerical measures to the relative importance of the criteria, and calculate weights (Wi);

(3) Grade the alternatives regarding these criteria (decision matrix);

(4) Process the grades with a weighted average to determine a ranking of each alternative.

The first step, i.e., criteria and alternatives definition, is deemed as the most important procedure in a MDCA. The literature review, and the following AV expectations analysis, provided the basis for the criteria formulation. The country (i.e., alternatives) selection, on the other hand, was built on geopolitical and economical relevance. Section 3 presents both in detail.

Then, in order to compare and define the relative importance of criteria, the scale proposed by Saaty (1980) was applied. The sum of each criterion's importance ratings provided its weight. So, countries are rated from 1 to 10 , according to their performance on each criteria. As some criteria are based on external data and calculations, a grade normalization was necessary to standardize the evaluation; thus, in every criteria, the country's rank is used. After the decision matrix definition, the weighted grades are calculated by the Equation 1, where the country $\mathrm{j}$ receives the rank Gij irrespective to the $\mathrm{i}$-criterion. The index $\mathrm{Ij}$ is then used to evaluate the countries.

$$
I_{j}=\sum_{i=1}^{n}\left(10-g_{i j}\right) \cdot w_{i}
$$

\section{Criteria and country definition}

As previously mentioned, the expected benefits and costs of AV implementation are bounded to a set of assumptions. Based on the literature review, and in particular in the work from Litman (2018) and Fagnant and Kockelman (2015), these main requirements were translated in country evaluation metrics and, consequently, evaluation criteria. Additionally, a stakeholders' analysis (as proposed by KLYNVELD PEAT MARWICK GOERDELER, 2012, shown in Figure 3) complemented the analysis and ensured that the main concerns and conditions regarding autonomous mobility were addressed. Table 1 summarizes the criteria; the requirements were split into five main categories, in which the criteria are equally weighted for simplicity.

Furthermore, Table 1 presents the weighted importance of each main category. The values were obtained through method described in Section 2.2., i.e. pairwise comparison using the scale proposed by Saaty (1980). Higher values mean that the category is more important.

Likewise, a set of requirements based on political and economic relevance guided the country selection. The current list includes nine countries: Australia, Brazil, China, Germany, Japan, Singapore, South Africa, United Arab Emirates (UAE) and the United States of America (USA).

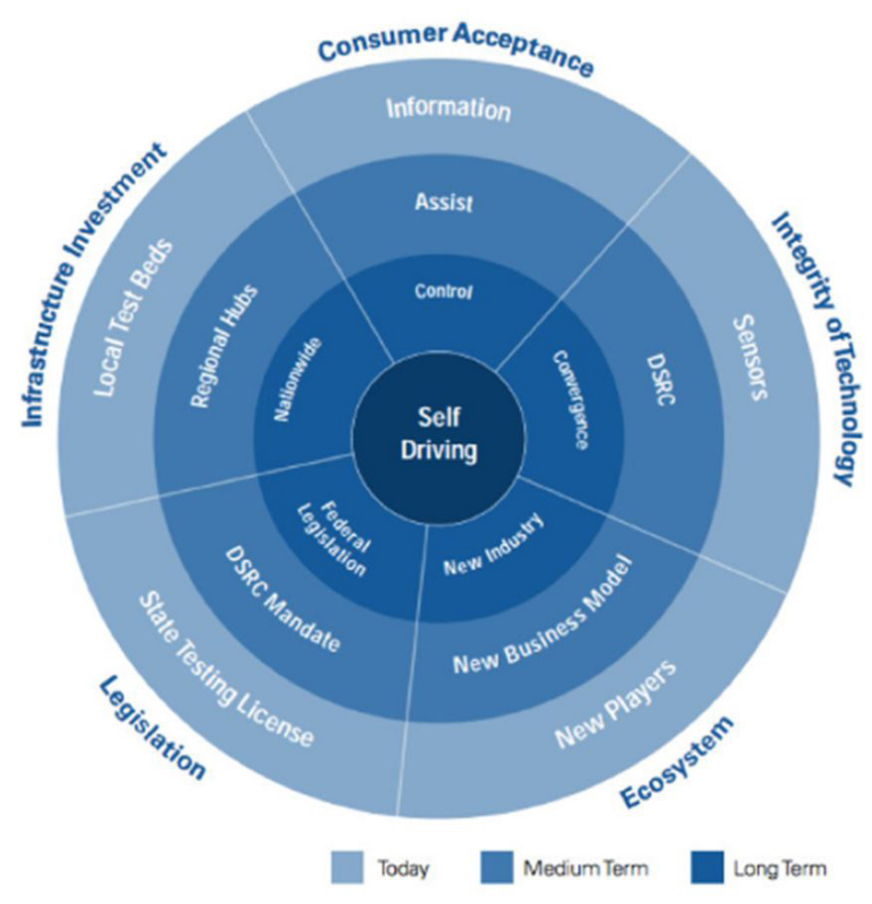

Figure 3. Stakeholders' analysis framework: basis for criteria formulation (KLYNVELD PEAT MARWICK GOERDELER, 2012). 
Table 1. Possible metrics for countries' evaluation, based on assumptions and expected benefits surrounding AVs.

\begin{tabular}{|c|c|c|}
\hline Topic (Weight) & Assumption/Requirements & Criteria \\
\hline Technology readiness $(\mathrm{T}-0.21)$ & $\begin{array}{l}\text { AV technology development and testing are } \\
\text { mature enough to deploy the vehicles in three } \\
\text { years }\end{array}$ & $\begin{array}{l}\text { T1: Current research efforts (public and private) } \\
\text { T2: Companies investing and testing in AV are present/head } \\
\text { quartet in the country } \\
\text { T3: AV-related patent production } \\
\text { T4: Technology availability }\end{array}$ \\
\hline Legislation $(\mathrm{L}-0.47)$ & $\begin{array}{l}\text { Countries will adapt their laws to cover issues } \\
\text { regarding AVs, from testing to accident liability }\end{array}$ & $\begin{array}{l}\text { L1: Existence of AV regulation, and to which extent } \\
\text { L2: Dedicated AV government branches } \\
\text { L3: Government's ability to change at quick pace } \\
\text { L4: Efficiency of legal systems }\end{array}$ \\
\hline \multirow[b]{2}{*}{ Improved mobility $(\mathrm{M}-0.05)$} & People will trust a machine's judgement & M1: Trust, adoption and acceptance of new technologies \\
\hline & Enabled by shared-use model & $\begin{array}{l}\text { M2: Penetration of shared-use transportation systems }+ \\
\text { Security }\end{array}$ \\
\hline \multirow{3}{*}{$\begin{array}{l}\text { Ownership and Operating Costs } \\
(\mathrm{C}-0.05)\end{array}$} & $\begin{array}{l}\text { High initial and maintenance costs could be } \\
\text { covered privately }\end{array}$ & $\mathrm{C} 1$ : Economic indicators \\
\hline & Specialized, highly complex maintenance & C2: Qualified working force availability \\
\hline & $\begin{array}{l}\text { Reduced insurance (due to increased safety) } \\
\text { and fuel costs }\end{array}$ & $\begin{array}{l}\text { C3: Insurance policies, electric vehicle incentives, power } \\
\text { matrix and costs }\end{array}$ \\
\hline \multirow[t]{2}{*}{ Traffic Safety $(\mathrm{S}-0.21)$} & $\begin{array}{l}\text { Road quality, dedicated lanes, signalling, } \\
\text { connectivity }\end{array}$ & S1: Infrastructure \\
\hline & Risks of malicious hacking & S2: Cybersecurity \\
\hline
\end{tabular}

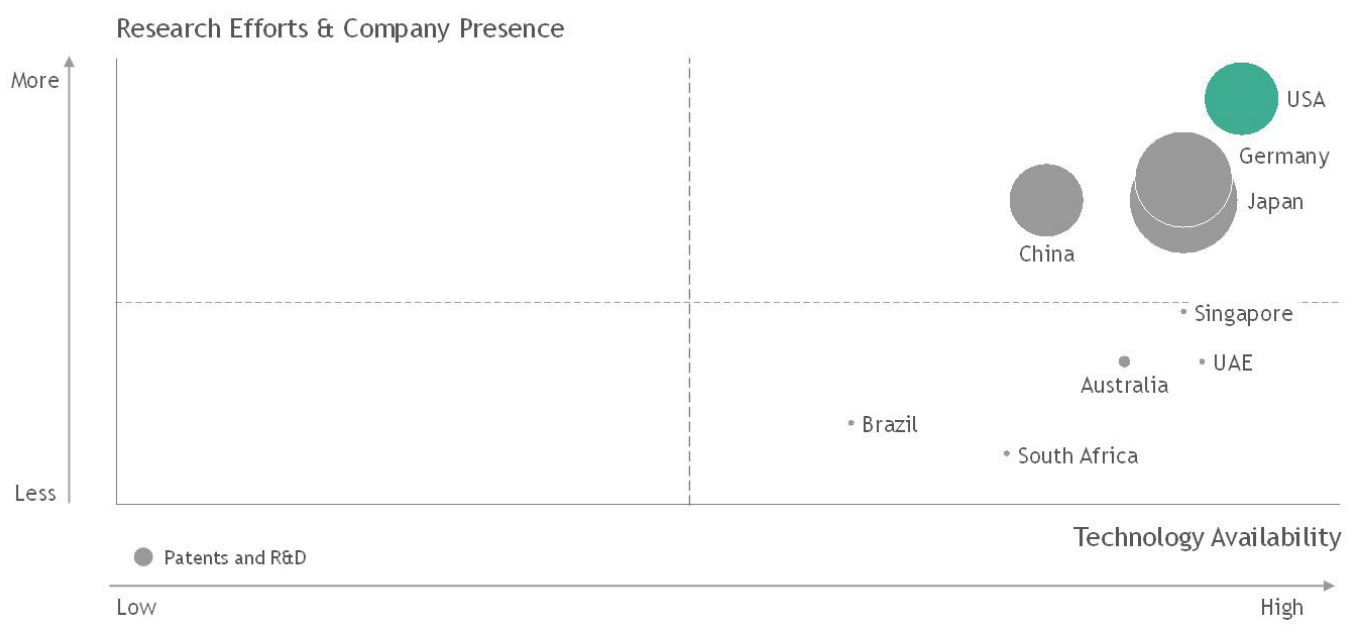

Figure 4. Countries' performance regarding the Technology Readiness (T) macro criterion.

\section{Results}

This section presents the results of the countries' evaluation regarding their AV-readiness. The majority of the analysis and evaluations were elaborated by the author; when not (i.e., based on an index provided by an external source), the text explicitly displays the analysis' source. The detailed evaluation is not presented in this paper due to space limitations.

Figure 4 illustrates the performance of each country in the technology readiness dimension. The y-axis displays the compound evaluation of the number of research efforts (T1) and companies' HQ (T2), as a proxy of the national market interest in AVs. The former was based on Bloomberg's
Aspen Initiative (BLOOMBERG, 2018), which mapped AV research groups around the world, and the ranking provided by The Automated Driving Community (THE AUTOMATED DRIVING COMMUNITY, 2017), which ranks the best universities globally for AV-related research. Automotive and technology industry powerhouses - i.e., USA, Germany and Japan, followed by China - lead the group.

In the interest of creating an exhaustive list of the companies and start-ups currently working on $\mathrm{AVs}$ or adjacent technologies (T2), multiple references were consulted. A collection organized by Vision Systems Intelligence (VISION SYSTEMS INTELLIGENCE, 2016), listed 124 well-established companies which have partially 
allocated their resources in autonomous mobility. Besides firms developing full autonomous solutions, companies focused on image processing, sensor, connectivity, mapping, algorithms, cybersecurity, or development tools were considered. However, it was noted that this revolutionary environment naturally attracts newcomers, with unique business models and technology proposals. Thus, the start-up focused list formulated by Comet Labs (COMET LABS, 2018) complemented the companies per country analysis. Finally, in order to reiterate the results, the report by Abuelsamid, Alexander and Jerram (2017) was once again examined.

The $\mathrm{x}$-axis compares the technology availability (T4) in each country, according to WEF's (WORLD BANK, 2018) analysis. This measurement indicates how fast AVs could be available to the population of a certain area, compared to other regions. A correlation between development levels and technology availability is observed.

Finally, the bubble diameter indicates the countries' relative performance in the AV-related patents criterion (T3).

To evaluate this criterion, Patent Insight Pro's (PATENT INSIGHT PRO, 2016) report on patent origin and coverage proved itself useful. By searching for control mechanisms, anti-collision systems, and breaking mechanisms, the authors were able to identify and categorize patents according to their assignees' country of origin. Thus, the data provided an overview on the technology's distribution. As expected, a significant gap among patent production is noted, as they were concentrated in developed countries with leading technology production and scale.

Figure 5 shows the AV-legislation performance. The y-axis measures the government change readiness (L3), an index provided by KPMG (KLYNVELD PEAT MARWICK GOERDELER, 2017) to evaluate whether governments' flexibility towards a new technology's ambiguity. Smaller countries with one-levelled, tech-driven governments (i.e., Singapore and UAE) tent to react faster and more precisely to change. The $\mathrm{x}$-axis combines the countries' current AV legislation (L1), and the general efficiency of law making bodies (L4), as perceived by WEF (WORLD BANK, 2018). The formed required a countryspecific evaluation to identify whether local governments are committed to adapt the current legislation to allow AVs in the public roads, and to deal with potential issues that may arise from this disruptive technology. The analysis was concentrated in legislation that enables testing and development of vehicles, as well as amendments in product liability claims to include autonomous technology. Developed countries scored better in both metrics, by preparing their legal systems for testing AVs, and not restricting the technology design in the development phase.

The bubble diameter displays the quantity of AV-government branches, and their performance (L2), as another proxy of the federal interest in enabling AVs. For that, a research on government dedicated departments, groups, commissions, or any equivalent branch to study public policies surrounding AVs, guiding legislation and development was conducted.

Two reactions derive from the Figure: the change-aversion of some governments (e.g., Brazil and South Africa) may results in a reactive behaviour regarding new technologies, as both countries also score poorly on legislation and efficiency of law making bodies. In contrast, countries with proactive, change-ready governments tent to respond better to technological challenges, elaborating laws and guiding public policies before practical issues arise, and creating a prosperous environment for technical development.

Figure 6 illustrates the performance of each country in the improved mobility dimension. The y-axis measures the consumer sentiment towards AVs (M1) through the percentage of people willing to ride in a driverless vehicle as studied by Deloitte (2017), Schoettle and Sivak (2014),

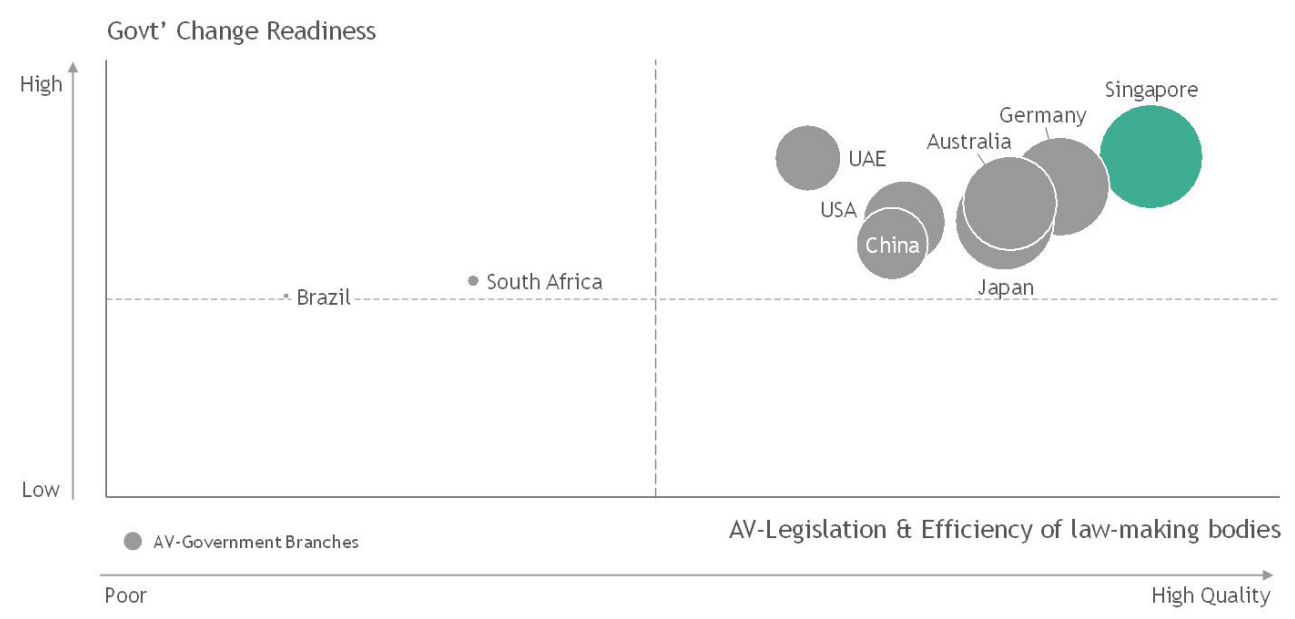

Figure 5. Countries' performance regarding the Legislation (L) macro criteria. 
WEF (WORLD BANK, 2015). Interestingly enough, Brazil - a country where discussions about AVs seldom happen, and the majority of population is uninformed about the technology - boasts the highest acceptance. The $\mathrm{x}$-axis translates the shared-used model feasibility (M2), by measuring the adoption rates of such services (DALIA RESEARCH, 2017), and the country's security levels (WORLD BANK, 2018) to investigate the vandalism risks. This impacts the performance of developing countries, as Brazil and South Africa. In countries that are both safer and with significant ride hailing penetration (e.g., Singapore, UAE, China), the likelihood of a successful AV shareduse model implementation increases - and so does the probability of reduced congestion and cost.

Figure 7 illustrates the performance of each country in the ownership and operating costs dimension. The qualified working force availability (C2), as measured by WEF (WORLD BANK, 2018), is displayed on y-axis, indicating whether the country is able to offer the complex maintenance services required by AVs. Countries with well-established educational systems and high tertiary education enrolment rates scored well in this dimension. The $\mathrm{x}$-axis translates the GDP per capita, in purchase power parity terms (C1), a proxy to evaluate whether private ownership of such vehicles is feasible, as provided by CIA (CENTRAL INTELLIGENCE AGENCY, 2018), in absolute terms.

The bubble diameter represents the possibility of cost of ownership reduction (C3), measured through current penetration rate of Usage Based Insurance (UBI), and incentives towards electric vehicles (EV). A safer traffic environment and a potentially reduced number of private vehicles will lower insurance premiums, and



Figure 6. Countries' performance related to the Improved Mobility (M) macro criterion.

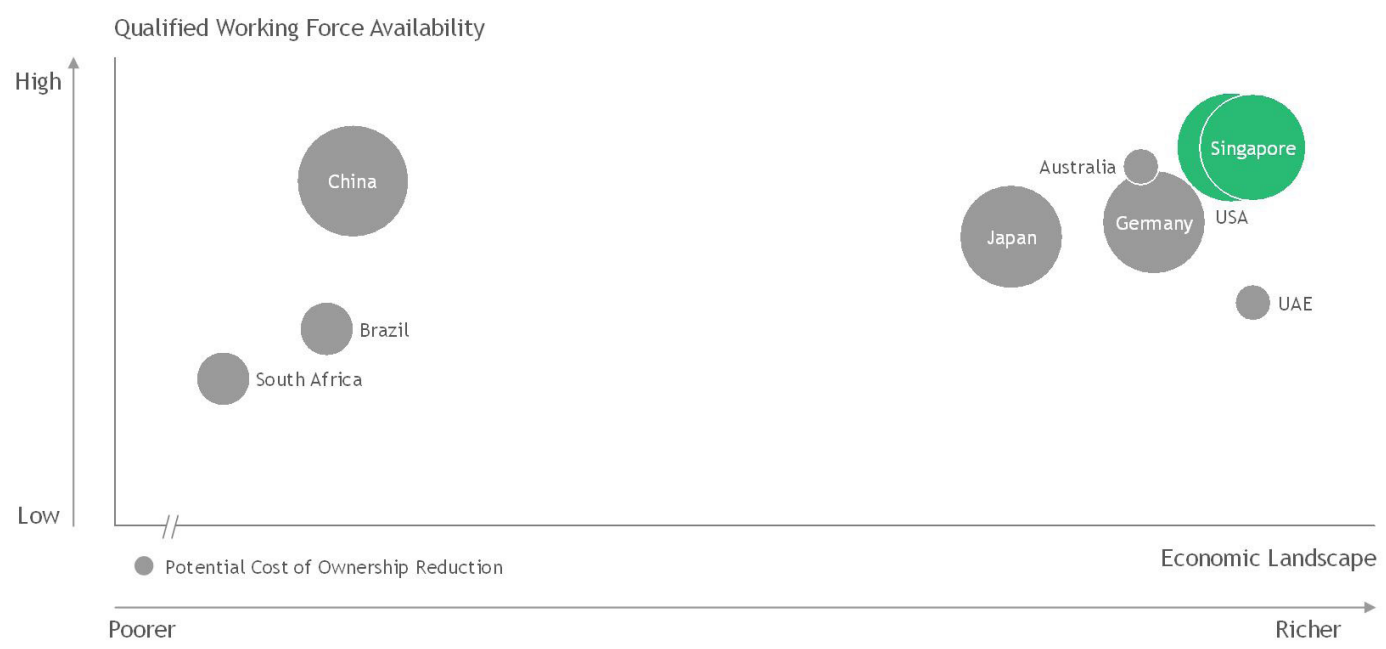

Figure 7. Countries' performance related to Ownership and Operating Costs (C) macro criteria. 
shift the insurance business as a whole, as the offering of usage-based, cybersecurity, and product liability insurance for OEMs is expected to increase. Even though the pricing dynamics of this market are complex, the current usage rates of UBI can be used as a proxy of how up to date actuarial models of the countries' main insurances are. Pay As You Drive (PAYD) and Pay How You Drive (PHYD) businesses models price insurances dynamically, based on the drivers' current behaviour; thus, they demand expertise in big data, analytics, and telecommunications. Ptolemus (2016) provided data on UBI distribution. Furthermore, costs reductions from EV-incentives are also expected, as autonomous vehicles will likely be electric or hybrid. The financial incentives and the EV-share in registrations per country data was drawn from three different reports (INTERNATIONAL ENERGY AGENCY , 2017a; LAND TRANSPORT AUTHORITY, 2017; DOLLARS AND SENSE, 2017).

Some developed nations - namely UAE and Australia do not show any significant financial incentive towards EVs, which might compromise the adoption of $\mathrm{AVs}$ on the long run. While China boasts the largest cost reduction potential due to centralized incentives to EVs, USA and Singapore have significantly larger buying power, which could benefit private AV ownership.

Finally, Figure 8 illustrates the performance of each country in the traffic safety dimension. The y-axis measures the commitment to cybersecurity (S2), as measured by ITU (INTERNATIONAL TELECOMMUNICATIONS UNION, 2017b). By considering legal, technical, organizational, capacity building and cooperation aspects, the index shows the gap in the level of cybersecurity engagement between different regions. While commitment in developed countries remains very high in the legal (e.g., data privacy)

and technical fields in particular, the challenging situation in underdeveloped regions shows the need for continued engagement and support. Exceptions are made for China and UAE, which are still maturing their defence and legal systems regarding the matter.

The $\mathrm{x}$-axis translates the quality of the country's infrastructure (S1). The assessment considers three dimensions: transport (i.e., quality of roads), electricity (i.e., quality of supply) and digital infrastructure (i.e., mobile network coverage, secure internet servers), as measured by WEF (WORLD BANK, 2018). Even though $90 \%$ of its cities have $4 \mathrm{G}$ coverage, Brazil's extremely poor road quality and unreliable servers make the country take the bottom place on infrastructure. In contrast, Singapore, Japan and UAE's almost perfect scores are due to high quality digital infrastructure and well-maintained roads, a result of effective public investments. As observed in the other analyses, there is a strong correlation between the ranking and overall economic development - which, as expected, leads to higher infrastructural quality.

Table 2 displays the combined results, organized according to the countries' final scores in descending

Table 2. Final Results.

\begin{tabular}{|l|c|c|c|c|c|c|c|}
\hline \multicolumn{1}{|c|}{ Country } & T & L & M & C & S & Total & Rank \\
\hline Singapore & 5 & 1 & 3 & 1 & 1 & 7.97 & 1 \\
\hline Germany & 2 & 2 & 7 & 4 & 6 & 6.73 & 2 \\
\hline Japan & 3 & 3 & 8 & 5 & 3 & 6.58 & 3 \\
\hline USA & 1 & 6 & 6 & 1 & 3 & 5.89 & 4 \\
\hline Australia & 7 & 4 & 4 & 5 & 6 & 4.84 & 5 \\
\hline UAE & 6 & 5 & 1 & 7 & 6 & 4.63 & 6 \\
\hline China & 4 & 7 & 2 & 3 & 7 & 4.05 & 7 \\
\hline South Africa & 8 & 8 & 8 & 9 & 9 & 1.72 & 8 \\
\hline Brazil & 8 & 9 & 5 & 8 & 8 & 1.66 & 9 \\
\hline
\end{tabular}

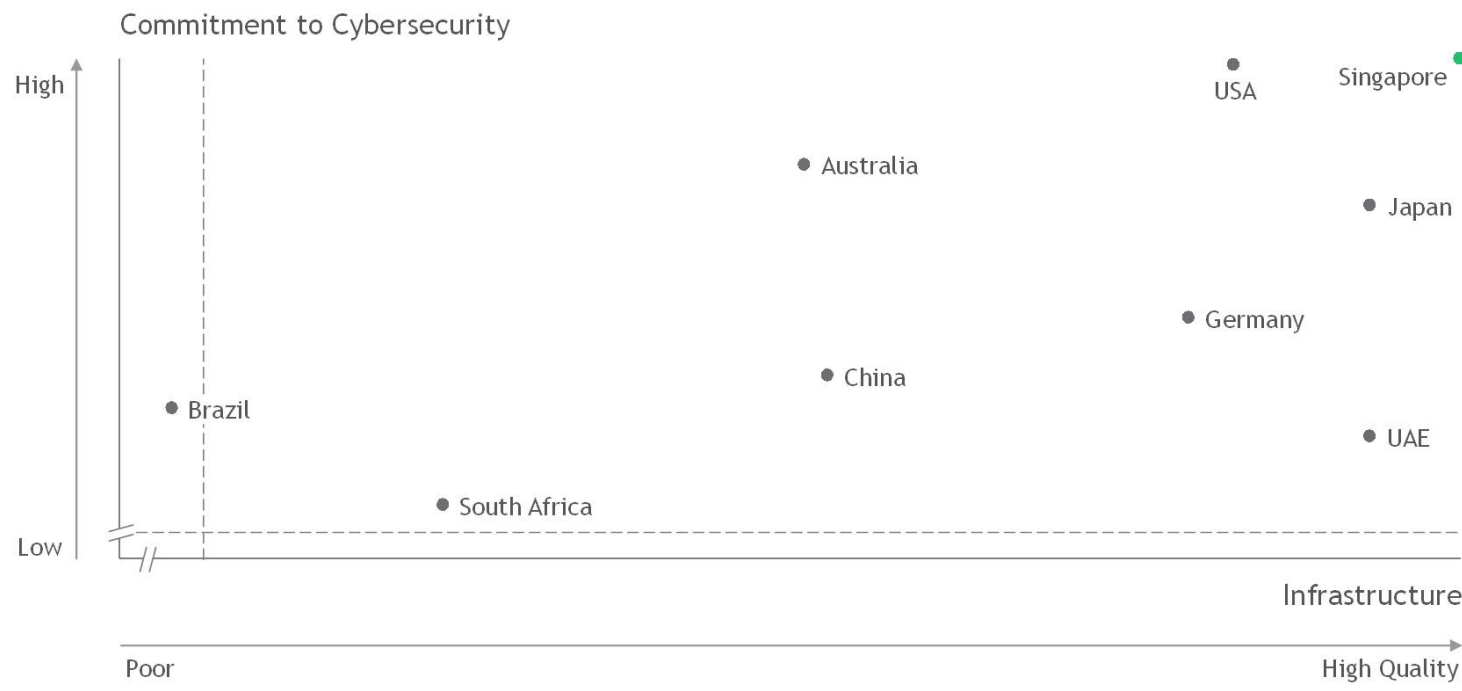

Figure 8. Countries' performance regarding the Traffic Safety (S) macro criterion. 
order. A higher score means that the country is more likely to host the AV implementation first. These rankings were obtained from the average ranking in each macro-criterion. In order to integrate the weights for each topic correctly, the grade associated to each rank (that is, 10 - rank value) was multiplied by the weights.

The first four countries - Singapore, Germany, Japan and USA - appear to be equally ready to host the AV revolution. However, due to its small-scale territory, and centralized government efforts towards a "Smart Nation" goal, Singapore's pace towards the autonomous mobility revolution is remarkably faster. Germany, Japan and USA leverage their technical capabilities, state-of-the-art infrastructure, and industrial development focused governments to lead the AV revolution not only within their countries, but also in a global level. Nevertheless, the low effectiveness of law making bodies in USA puts the country in an unfavourable position when compared to its counterparts.

An active government and favourable AV legislation placed Australia as the fifth country on the list - on the other hand, the lack of automotive industry, and the presence of disincentives towards electric mobility could potentially hinder the development of autonomous vehicles. A similar conclusion is drawn from UAE's ranking - while the society is positive about AVs, the lack of industry, legislation, incentives, and cybersecurity investments puts the revolution on hold. It is important to note, however, that the Middle Eastern country has multiple projects in their pipeline to revert this situation.

Finally, while China is the world's second largest economy and industrial powerhouse (WORLD BANK, 2018), its market and social reforms are still incomplete. This reflects on the developing infrastructure and legislation, and impact negatively on the efficiency of law making bodies, change readiness, and cybersecurity levels. On the other hand, the Asian country is known for its ability to quick implement new technologies due to its centralized government, which might be able to turn the scenario completely.

The bottom two countries - South Africa and Brazil still struggle to grow and overcome basic challenges, which range from high unemployment rates to widespread poverty. Thus, the likelihood of hosting the AV revolution remains low, or restricted to particular business models (e.g., freight transportation).

As previously mentioned, some correlation between overall economic development and the rankings was consistently observed (Figure 9). This matches expectations of developed countries leading the technology revolution, by leveraging their research and budget capabilities.

\section{Conclusions}

As initially proposed, this article provided a meaningful contribution in the field of public policies around AVs, by mapping the conditions and enabling factors of such implementation and evaluating their presence globally. The outputs, limitations and outlook of such work are discussed in the following paragraphs.

\subsection{Results and recommendations}

First, through the analysis of implementation predictions and requirements, a comprehensive list of assumptions regarding AVs was formulated. These understandings of beneficial conditions lead to the evaluation of AV-readiness in selected countries. However, the multi-criteria framework can be extended to other analyses regarding AVs, being a valuable method for public planners.

By setting the focus on the performance of nine selected countries regarding AVs, the investigation identified a few best practices, which can be implemented in other regions. Advantageous conditions in most prepared countries include:

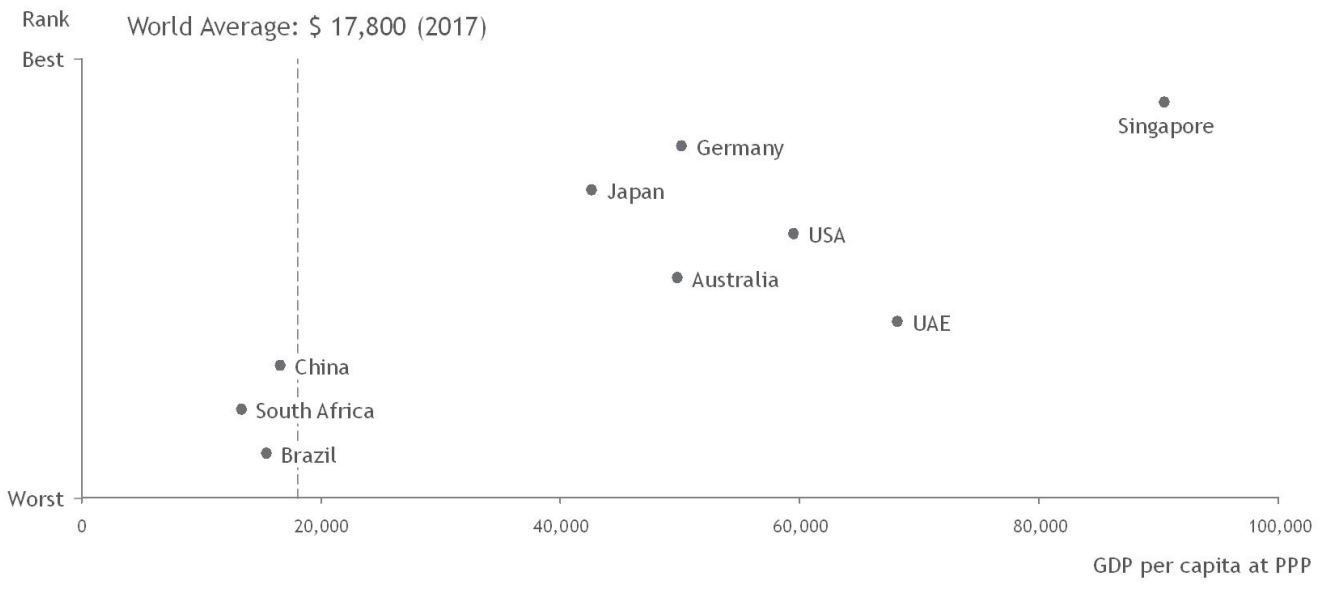

Figure 9. Correlation between final scores and GDP per capita at PPP. 
(1) Technology: Partnerships between governments, industry and research institutions; roadmaps to guide technical development; attractive environment for companies and start-ups;

(2) Legislation: creation of laws and guidance that foster AV development, instead of generating design/testing barriers; changes in product liability rules;

(3) Improved Mobility: implementation in an attractive way, raising consumer acceptance; incentives for shared-use of vehicles;

(4) Ownership and Operating Costs: high economic development; incentives for EVs;

(5) Traffic Safety: investments in road and network infrastructure and maintenance; proactive commitment to cybersecurity via legal and technical paths.

The study also revealed that such conditions are not equally spread around the globe. Thus, the benefits surrounding AVs' implementation should not be expected when the aforementioned conditions are not present. The analysis of best performing countries can, however, assist policy planners in their local efforts regarding AVs.

\subsection{Limitations and future work}

The high degree of uncertainty surrounding autonomous vehicles deployment, and in particular the current stage of technical development, leaves the present article with intrinsic limitations. For instance, the absences of a successful case study of widespread AV implementation to date constraints the analysis.

Additionally, in-depth investigations, which could include interviews and field studies, are yet to be done. Further concerns to be addressed by future studies include potential business models in each country other than public transportation, and alignment with current policies to democratize mobility. Likewise, the economic power of nations (expressed by metrics as total GDP) was not explicitly used as a criterion - but it might have a relevant impact on the governmental capacity of investing in AVs.

The results should be interpreted as a direction on each country's readiness for autonomous mobility, rather than an inference about the exact timing when this revolution will catch on. As in any ground-breaking technology deployment, planning and preparing are valuable skills, but predicting exactly how the implementation will happen is an impassable challenge.

\section{References}

ABUELSAMID, S.; ALEXANDER, D.; JERRAM, L. Navigant research leaderboard report: automated driving. Chicago: Navigant, 2017.
ACCENTURE. Autonomous driving - are OEMs losing the driver seat? Dublin: Accenture, 2015.

ANDERSON, J. M. et al. Autonomous vehicle technology: a guide for policymakers. Santa Monica: Rand Corporation, 2014.

BAGLOEE, S. A. et al. Autonomous vehicles: challenges, opportunities, and future implications for transportation policies. Journal of Modern Transportation, v. 24, n. 4, p. 284-303, 2016.

BLOOMBERG. Initiatives on cites and autonomous vehicles. 2018. Available from: <https://avsincities.bloomberg.org/>. Access in: 30 Mar. 2018.

CENTRAL INTELLIGENCE AGENCY - CIA. The world factbook. 2018. Available from: $<$ https://www.cia.gov/ library/publications/the-world-factbook/>. Access in: 10 Apr. 2018.

CLAMANN, M.; AUBERT, M.; CUMMINGS, M. L. Evaluation of vehicle-to-pedestrian communication displays for autonomous vehicles. In Proceedings of the 96th Annual Transportation Research Board Meeting, Washington, DC, 2017.

COMET LABS. 263 self-driving car startups to watch. 2018. Available from: $<$ https://blog.cometlabs.io/263-self-drivingcar-startups-to-watch-8a9976dc62b0>. Access in: 30 Mar. 2018.

DALIA RESEARCH. How the world moves. 2017. Available from: $<$ http://mobility.daliaresearch.com/dashboard $>$. Access in: 27 May 2018.

DELOITTE, A. Reality check on advanced vehicle technologies. 2017. Available from: <https://www2.deloitte. $\mathrm{com} /$ content/dam/Deloitte/at/Documents/automotive/ deloitte-global-automotive-consumer-study-2018.pdf $>$. Access in: 27 May 2017.

DOLLARS AND SENSE. NG, N. Do Electric. Vehicles make financial sense in Singapore? 2017. Available from: <https:// dollarsandsense.sg/evs-make-financial-sense-singaporeheres-electric-hybridpetrol-cars-compare/>. Access in: 27 May 2018.

ENG, $\mathrm{H}$. Embracing the future of land transportation: valuing flexibility in design and technology options for autonomous vehicle developments in Singapore. Massachusetts: Massachusetts Institute of Technology, 2017.

FAGNANT, D. J.; KOCKELMAN, K. Preparing a nation for autonomous vehicles: opportunities, barriers and policy recommendations. USA: Elsevier: 2015.

FUJIMOTO, T. The long tail of the auto industry life cycle. Journal of Product Innovation Management, v. 31, n. 1, p. 8-16, 2014.

IBUSUKI, U.; KOBAYASHI, H.; KAMINSKI, P. C. Localisation of product development based on competitive advantage of 
location and government policies: a case study of car makers in Brazil. International Journal of Automotive Technology and Management, v. 12, n. 2, p. 172-196, 2012.

INTERNATIONAL ENERGY AGENCY - IEA. Global EV Outlook 2017. 2017a. Available from: $<$ https://www.iea.org/ publications/freepublications/publication/globalEVOutlook 2017.pdf $>$. Access in: 27 May 2018.

INTERNATIONAL TELECOMMUNICATIONS UNION ITU. Global Cybersecurity Index (GCI). 2017b. Available from: <https://www.itu.int/dms pub/itu-d/opb/str/D-STRGCI.01-2017-PDF-E.pdf $>$. Access in: 27 May 2018.

KALRA, N.; PADDOCK, S. M. Driving to safety: how many miles of driving would it take to demonstrate autonomous vehicle reliability? Transportation Research Part A, Policy and Practice, v. 94, p. 182-193, 2016.

KLYNVELD PEAT MARWICK GOERDELER - KPMG. Self-driving cars: the next revolution. Amsterdam: KPMG, 2012.

KLYNVELD PEAT MARWICK GOERDELER - KPMG. Change readiness index. Amsterdam: CRI, 2017.

KLYNVELD PEAT MARWICK GOERDELER - KPMG. Autonomous vehicles readiness index. Amsterdam: AVRI, 2018.

KNIGHT, W. What Uber's fatal accident could mean for the autonomous-car industry. 2018. Available from: <https:// www.technologyreview.com/s/610574/what-ubers-fatalaccident-could-mean-for-the-autonomous-car-industry/> . Access in: 10 Apr. 2018.

LAND TRANSPORT AUTHORITY - LTA. Annual vehicle statistics 2017. 2017. Available from: <https://www.lta. gov.sg/content/ltagov/en/who_we_are/statistics_and publications/statistics.html> link. Access in: 27 May 2018.

LITMAN, T. Autonomous vehicle implementation predictions: implications for transport planning. Victoria: Victoria Transport Policy Institute, 2018.

LUSTGARTEN, P.; LE VINE, S. Public priorities and consumer preferences for selected attributes of automated vehicles. Journal of Modern Transportation, v. 26, n. 1, p. 72-79, 2018.

NATIONAL HIGHWAY TRAFFIC SAFETY ADMINISTRATION - NHTSA. Automated driving systems 2.0: a vision for safety. Washington: NHTSA, 2017.

OHNEMUS, M.; PERL, A. Shared autonomous vehicles: catalyst of new mobility for the last mile? Built Environment, v. 42, n. 4, p. 589-602, 2016.

PARDI, T.; CALABRESE, G. C. Editorial. International Journal of Automotive Technology and Management, v. 18, n. 2, p. 75-80, 2018.

PATENT INSIGHT PRO. Autonomous car-control mechanism. 2016. Available from: <http://www.patentinsightpro.
com/techreports/0416/Autonomous\%20Car-Control\%20 Mechanism.pdf $>$. Access in: 30 May 2018.

PTOLEMUS. Usage-based insurance supplier ranking 2016. 2016. Available from: <https://www.ptolemus.com/ubisupplier-rankings-2016/>. Access in: 27 May 2018.

RANDALL, T. Elon musk was wrong about self-driving Teslas. 2018. Available from: $<$ https://www.bloomberg.com/ news/articles/2017-10-25/can-tesla-make-up-for-autopilot-slost-year>. Access in: 10 Apr. 2018.

SAATY, T. L. The analytic hierarchy process. New York: McGraw-Hill, 1980.

SCHOETTLE, B.; SIVAK, M. Public opinion about selfdriving vehicles in China, India, Japan, the U.S., the U.K., and Australia. Michigan: University of Michigan, 2014.

THE AUTOMATED DRIVING COMMUNITY. 2025 AD. 7 universities that are pushing the boundaries of autonomous driving. 2017. Available from: <https:// www.2025ad.com/latest/top-universities-for-autonomousdriving/>. Access in: 10 Apr. 2017.

THE BOSTON CONSULTING GROUP - BCGa. Revolution in the driver's seat. Boston: BCGb, 2015a.

THE BOSTON CONSULTING GROUP - BCGb. Revolution versus regulation. Boston: $B C G b, 2015 b$.

TRIANTAPHYLLOU, E. Multi-criteria decision making methods. In TRIANTAPHYLLOU, E. Multi-criteria decision making methods: a comparative study. Boston: Springer, 2000. p. 5-21.

UNITED NATIONS ECONOMIC AND SOCIAL COUNCIL. Vienna convention on road traffic. Geneva: United Nations Economic and Social Council, 2017.

VANDERBILT, T. Autonomous cars through ages. 2018. Available from: <https://www.wired.com/2012/02/ autonomous-vehicle-history/>. Access in: 30 Mar. 2018.

VISION SYSTEMS INTELLIGENCE. The building blocks of autonomy. 2016. Available from: <https://ww1.prweb. com/prfiles/2016/06/08/13472308/Source_Vision_Systems_ Intelligence_Infographic.JPG >. Access in: 30 Mar. 2016.

WORLD BANK. The world bank in China. 2018. Available from: < http://www.worldbank.org/en/country/china/ overview>. Access in: 27 May 2018.

WORLD ECONOMIC FORUM - WEF. Self-driving vehicles in an urban context. 2015. Available from: <http://www3. weforum.org/docs/WEF_Press\%20release.pdf $>$. Access in: 27 May 2015.

WORLD ECONOMIC FORUM - WEF. 2017-2018 global competitiveness index. 2018. Available from: <https:// www.weforum.org/reports/the-global-competitivenessreport-2017-2018>. Access in: 30 Mar. 2018. 